\section{Geological Age of Gaudryina tailleuri in Northern Alaska}

For several years, in publications dealing with Alaskan biostratigraphy, an Early Albian age has been attributed to the Gaudryina tailleuri faunal zone ${ }^{1-3}$ of Alaska. The zone has, in fact, been equated with the whole of the Early Albian and the zone fossil G. tailleuri considered to be an Early Albian index form with restricted range.

Published records show that the only occurrence of G. tailleuri closely associated with an Early Albian ammonite, Beudanticeras (Grantziceras) affine, is in the type section of the Torok Formation where $G$. tailleuri lies about $100 \mathrm{~m}$ above the level at which this ammonite was found ${ }^{4,5}$. The provenance of this specimen is in doubt, for it was collected from the talus slope (personal communication from I. L. Tailleur). The only other published well dated occurrence of $G$. tailleuri is in beds of the Okpikruak Formation, with Buchia spp. above and below, thus dating it as no younger than Valanginian ${ }^{5}$. This occurrence does not seem to have been taken into account in previous statements on the range of $G$. tailleuri.

Investigation of samples collected by BP Alaska Ine. geologists on field surveys in 1964, 1965 and 1966 showed that $G$. tailleuri and associated species of the $G$. tailleuri zone occurred in association with Buchia 'sublaevis' (Valanginian) and B. mosquensis (M. Kimmeridgian to L. Portlandian). Only microfossil assemblages from beds containing the megafossils, preferably from the rock matrix adhering to the megafossils, were considered to be validly dated by the megafossils. Assemblages from beds laterally separated from the megafossil occurrences but believed on field evidence to correlate with them were considered to be insufficiently reliable and were excluded from this study of the relationship of the $G$. tailleuri zone to dated megafossil occurrences.

Some sections showed clearly that the G. tailleuri microfauna continued about $30 \mathrm{~m}$ stratigraphically above the top occurrences of Valanginian Buchia specimens, but no megafossil dating of the top of the microfauna could be obtained and it was not known whether the $G$. tailleuri fauna extended into the Albian. Moreover, there is a distinct interval, demonstrated in well sections from Naval Petroleum Reserve 4, which contains only Radiolaria, chiefly pyritized, called by Bergquist ?Lithocampe sp. and ? Dictyomitra sp., and rare non-diagnostic agglutinating foraminifera, separating the $G$. tailleuri zone fauna from the Verneuilinoides borealis zone fauna, which is generally accepted as Middle to Late Albian.

Recent palynological evidence indicates some top occurrences of $G$. tailleuri in sections to be no younger than Barremian or possibly Aptian.

In some Early Neocomian sediments, elements such as Trochammina canningensis, previously believed to be confined to the Jurassic, are found associated with $G$. tailleuri fauna and with Buchia 'sublaevis'.

This evidence shows that the $G$. tailleuri fauna can be closely associated with Jurassic fauna and that $C$. tailleuri ranges from Middle Kimmeridgian to Barremian, possibly to Aptian and doubtfully to Early Albian. It can no longer be accepted as an Early Albian index fossil.

I thank Dr H. R. Bergquist of the US Geological Survoy for his examination of critical specimens of $G$. tailleuri and for his criticism and advice.

\section{W. V. RAMSAY}

BP Research Centre,

Chertsey Road,

Sunbury on Thames, Middlesex.

Received April 5, 1970.

${ }^{1}$ Bergquist, H. R., Geol. Soc. Amer. Bull., 67, No. 12, part 2 (1956).

${ }^{2}$ Bergquist, H. R., US Geol. Survey Prof. Paper 302-D (1966).

3 Tappan, H. L., US Geol. Survey Prof. Paper 236-C (1962).

4 Detterman, R. L., Bickel, R. S., and Gryc, G., US Geol. Survey Prof. Paper 303-E (1963).

Patton, W. W., and Taillesir, I. L., US Geol. Survey Prof. Paper 303-G (1964).

\section{Molecular Model of Drag Reduction by Polymer Solutes}

Toms ${ }^{1}$ has shown that in turbulent flow above the critical Reynolds number the drag is substantially reduced by adding a small arnount of high polymer solute to the liquid $^{2-14}$. In some cases, there is also a remarkable shift of the onset of turbulence to higher Reynolds number ${ }^{15,16}$ with a corresponding reduction of drag. Typical drag reductions of over 50 per cent have been achieved in pipes, on immersed moving bodies and on ship hulls by the addition of 20 p.p.m. by weight of 'Polyox $W S R 30 \mathrm{I}$ ', which is an unbranched polyethylene oxide of approximate mole. cular weight $4 \times 10^{6}$. Larger doses of polymer solute produce little additional effect. A minor effect of this type-about 4 per cent drag reduction-can also be achieved by the addition of a relatively large amount of very fine sand $17-19$.

The additive always increases the drag in the laminar flow range because it increases the viscosity of the liquid from $\eta_{0}$ for pure liquid to $\eta>\eta_{0}$ for the solution or suspension. In the concentration range concerned, this increase is relatively small, and for all practical purposes the viscosities of the solvent and solution are very nearly identical.

Attempts to explain this turbulence depression have been almost exclusively based on the viscosity dependence of vortex diffusion, and particularly on the non-Newtonian or viscoelastic properties of a polymer solution ${ }^{17,20-22}$. A simple calculation of a typical case, however. shows that the expected riscoelasticity is too small to explain the observed effects. A 20 p.p.m. solution of polyethylene oxide of $M=4 \times 10^{6}$ yields a relative viscosity $\eta_{\text {rel }}=1.04$ The viscoelastic effects therefore do not amount to more than 4 per cent of the total viscosity effects, compared with the 96 per cent contribution of the Newtonian viscosity of the solvent (water). It is hard to believe that such a small non-Newtonian effect can so drastically modify the hydrodynamic properties of the system.

The most likely explanation seems, therefore, to be based on the behaviour of individual molecules of the solute and not on the bulk properties of the solution. The randomly coiled macromolecule may take so much energrfrom the vortex that its furthor growth is efficientlyreduced if the energy dissipation is not based on the conventional response of such particles to the laminar flow with a transverse gradient, but on the response to the actual flow regime of the vortex.

The vortex moves very nearly as freely through the polymer-free volumes of the solution as through a pure liquid, although during such motion adjacent polymer molecules rotate and deform as required by the local value of the gradient created by the rortex superimposed on the bulk flow. When the vortex hits a macromolecular coil, however, the deformation of the latter may become extreme because of the extremely rapid change of velocity. gradient and type of flow. The purely rotational flow $v=$ $(-\omega y, \omega x, 0)$ in the core $(G=0)$ turns over in the purely dilatational flow $v=\omega r_{0}{ }^{2}\left(-y / r^{2}, x / r^{2}, 0\right)$ around the core. The randomly coiled macromolecule is first exposed to dilatational flow with longitudinal gradient which expands the coil considerably more than a flow with transverse gradient. The viscosity contribution of the expanded coil23-26, is therefore much greater than that suggested by $\eta_{\text {rel }}$ and this damps the vortex. The effect continues when the highly expanded coil partially enters the core of the vortex.

Fig. 1 shows a schematic model of such a deformation. One end of the macromolecule lies in the core of the vortex and the other one is outside it, and this strains the intermediate chain section. The extension may take place a long way from the initial r.m.s. end-to-end distance, $k$, up to a substantial fraction of the extended chain length $L$, for example, for polyethylene oxide of $M=4 \times 10^{6}$, from $h=3,000$ to $L=340,000 \AA=34 \mu \mathrm{m}$. A material connexion established by the long macromolecule between two 